\title{
Article \\ Performance of High Efficiency Avalanche Poly-SiGe Devices for Photo-Sensing Applications
}

\author{
Yuang-Tung Cheng ${ }^{1}{ }^{\mathbb{D}}$, Tsung-Lin Lu ${ }^{1}$, Shang-Husuan Wang ${ }^{1}$, Jyh-Jier Ho ${ }^{1, * \mathbb{C}}$, Chung-Cheng Chang ${ }^{1}$, \\ Chau-Chang Chou ${ }^{2} \mathbb{D}$ and Jiashow $\mathrm{Ho}^{3}$
}

1 Department of Electrical Engineering, National Taiwan Ocean University, No.2, Pei-Ning Rd., Keelung 202, Taiwan; yt5868@gmail.com (Y.-T.C.); zonglinlu1997@gmail.com (T.-L.L.); ricesimonwong@gmail.com (S.-H.W.); ccchang@mail.ntou.edu.tw (C.-C.C.)

2 Department of Mechanical \& Mechatronic Engineering, National Taiwan Ocean University, No.2, Pei-Ning Rd., Keelung 202, Taiwan; cchou@mail.ntou.edu.tw

3 Department of Electrical Engineering, University of California, Los Angeles, CA 90095, USA; jth72507@gmail.com

* Correspondence: jackho@mail.ntou.edu.tw; Tel.: +886-92-8346560; Fax: +886-22-4635408

check for updates

Citation: Cheng, Y.-T.; Lu, T.-L.; Wang, S.-H.; Ho, J.-J.; Chang, C.-C.; Chou, C.-C.; Ho, J. Performance of

High Efficiency Avalanche Poly-SiGe Devices for Photo-Sensing Applications. Sensors 2022, 22, 1243 https://doi.org/10.3390/s22031243

Academic Editor: Hugo Águas

Received: 22 December 2021

Accepted: 3 February 2022

Published: 7 February 2022

Publisher's Note: MDPI stays neutral with regard to jurisdictional claims in published maps and institutional affiliations.

Copyright: (C) 2022 by the authors. Licensee MDPI, Basel, Switzerland. This article is an open access article distributed under the terms and conditions of the Creative Commons Attribution (CC BY) license (https:// creativecommons.org/licenses/by/ $4.0 /$ )

\begin{abstract}
This paper explores poly-silicon-germanium (poly-SiGe) avalanche photo-sensors (APSs) involving a device of heterojunction structures. A low pressure chemical vapor deposition (LPCVD) technique was used to deposit epitaxial poly-SiGe thin films. The thin films were subjected to annealing after the deposition. Our research shows that the most optimal thin films can be obtained at $800{ }^{\circ} \mathrm{C}$ for $30 \mathrm{~min}$ annealing in the hydrogen atmosphere. Under a $3-\mu \mathrm{W} / \mathrm{cm}^{2}$ incident light (with a wavelength of $550 \mathrm{~nm}$ ) and up to $27-\mathrm{V}$ biased voltage, the APS with a $\mathrm{n}^{+}-\mathrm{n}-\mathrm{p}-\mathrm{p}^{+}$alloy $/ \mathrm{SiO}_{2} / \mathrm{Si}-$ substrate structure using the better annealed poly-SiGe film process showed improved performance by nearly $70 \%, 96 \%$ in responsivity, and $85 \%$ in quantum efficiency, when compared to the nonannealed APS. The optimal avalanche multiplication factor curve of the APS developed under the exponent of $n=3$ condition can be improved with an increase in uniformity corresponding to the APS-junction voltage. This finding is promising and can be adopted in future photo-sensing and optical communication applications.
\end{abstract}

Keywords: poly-silicon germanium (poly-SiGe); low pressure chemical vapor deposition (LPCVD) system; responsivity; quantum efficiency; avalanche multiplication factor

\section{Introduction}

Traditionally, optical devices utilizing photomultiplier tubes (PMT) have been the mainstream [1-4], but with the development of applications, such as optical communication [1], 3-D image sensing [2], astronomical and biological detection [3,4], the demand for a high-performing, robust optical sensor has become more prevalent. The conventional PMT optical devices are oftentimes bulky, fragile, and sensitive to magnetic fields, thus requiring very high operation voltages and high-power consumption. In recent years, these disadvantages of PMT have put a limit on detection rate, high time resolution, and high spatial density [5].

A promising alternative to the PMT is the avalanche photosensor (APS), which has a simple structure and is compatible with the CMOS standard manufacturing process. It can be directly integrated in an IC chipset, which greatly reduces its size. Furthermore, the materials used in an APS have high-sensitivity, high-resolution, fast response-speed, low power-consumption, and relatively cheap manufacturing [6-8]. Presently, the silicon-based (Si-based) APS is one of the most popular photo-sensing technologies. This development technique can limit the sensitivity, response-speed, and device geometry of the end-product. By using a nano-opto-electro-mechanical system (NOEMS) fabrication process for integrated circuits (ICs), the APS allows the combination of light and electronic processing 
circuits (such as amplifier and filter circuits) to improve sensitivity [9,10]. However, while speed can be increased by reducing the time it takes to pass through the thin photo-sensing layer, it is more difficult to collect additional light in a single-chip Si-based system. This leads to a compromise between the quantum efficiency (QE) and the photosensor response speed [11]. In the photo-sensing market, only silicon APS promises outstanding performance with high current amplification and high optical response [12-16]. This optical response can be extended to the visible spectrum.

Due to their inherently higher mobility than pure silicon ( $\mathrm{Si}$ ), silicon germanium ( $\mathrm{SiGe}$ ) thin films are better suited for use in photo-sensing and optical communication devices [17]. In particular, poly-SiGe (p-SiGe) films are a great candidate for Si-based photo-sensing due to their compatibility with Si and high optical absorption. Additionally, poly-SiGe films are also a promising alternative to amorphous-SiGe (a-SiGe) films due to their compatibility with Si, as well as their lower growth temperatures, higher mobility, and higher heat resistance coefficients. These are excellent properties for its production in the manufacturing industry [18-22]. The APS devices that are made with Poly-SiGe thin films are an efficient way to improve the detection performance in avalanche applications.

Due to the stress caused by the $4.2 \%$ SiGe lattice mismatch and significant temperature growth, deposition temperature is an important factor in the APS performance for polySiGe films [23]. Poly-SiGe films with a narrow bandgap lead to unacceptably high defect densities, especially through dislocations, in the deposited films, and most techniques in traditional solid-phase crystallization processes (such as molecular beam epitaxy, rapid thermochemical vapor deposition, or pulsed laser-assisted deposition techniques) have films with poor step coverage. S. Kobayashi et al. demonstrated that the flow ratio of working gas, $\mathrm{H}_{2}$ and $\mathrm{Ar}$, affects the microstructure and optoelectronic properties of the formed poly-SiGe films [24]. The key role of hydrogen in the poly-SiGe layers growth process is to reduce the defects in the crystalline materials at a certain temperature [25]. On the growth surface, the high $\mathrm{H}$-coverage reduces the number of Si dangling bonds. As a result, it can effectively increase the surface mobility of the grown precursor, allowing free radicals to find a more stable position, and promote crystallization. Additionally, the passivation effect of $\mathrm{H}_{2}$ can also be used for improving the grain boundary of the better efficiency in the device applications [26,27].

However, the state of crystallization depends on the Ge content or the deposition process, and the location of the nucleation site affects the microstructure of the films [28]. Controlled heterogeneous nucleation to form a poly-SiGe quantum confinement effect can be achieved by the thermal oxidation of the poly-SiGe film. Quantum dots allow precise size control and induce quantum confinement effects as they vary with electronic structure and band structure for optoelectronic applications [29,30]. The APS can improve the response rate due to its internal carrier multiplication mechanism. Since poly-SiGe films have a good ionization coefficient ratio, they are one of the best materials for the fabrication of an APS [31,32].

Numerous techniques for SiGe thin layer deposition for photo-sensing applications were investigated. These techniques included ultra-high vacuum and reduced pressure chemical-vapor deposition (UHVCVD or RPCVD) [33], low-pressure chemical-vapor deposition (LPCVD) [34-36], plasma-enhanced chemical-vapor deposition (PECVD) [37-39], and pulsed laser deposition (PLD) [40]. The key technology developed in this study is a selective LPCVD epitaxial growth of poly-SiGe thin films at low-temperature. A LPCVD can adjust the Ge content of the poly-SiGe film by changing the flow rate ratio of silane $\left(\mathrm{SiH}_{4}\right)$ and germane $\left(\mathrm{GeH}_{4}\right)$. The boundary layer deposited by a LPCVD reactor has a low molecular density [41], which is different from those of the other CVDs. This low-cost action forms conformal films with high-aspect step coverage, which is beneficial to the APS system with high detecting performance.

The poly-SiGe layers deposited on Si substrate we reference to other authors' studies [42], the reason for the increase in grain size is not observed at annealing temperatures lower than $1000^{\circ} \mathrm{C}$. Colace et al. [43] and Luan et al. [44] effectively reduced thread dislo- 
cations by thermal annealing. According to the reference literature [42-45], the annealing temperature between $700{ }^{\circ} \mathrm{C}$ and $900{ }^{\circ} \mathrm{C}$ is adjusted for optimally transferring the surface morphology from the thermal energy to the crystalline structure. An as-deposited SiGe film has a poly-structure and will undergo post-annealing to improve its quality. Crystallization is induced at the interface between the layer and the crystalline substrate by thermal annealing in order to form a uniform layer.

In order to obtain the optimum APS growth conditions, we investigated various annealing parameters, such as the annealing temperature and annealing time of the polySiGe films. The proposed structure consists of indium-tin oxide (ITO)/ poly-Si ${ }_{0.8} \mathrm{Ge}_{0.2}$ films and aluminum $(\mathrm{Al})$ / silicon dioxide $\left(\mathrm{SiO}_{2}\right) / \mathrm{Si}$-substrate, which is a reach-through $\left(n^{+}-n-p-p^{+}\right)$structure. The photocurrent of the APD element increases with an increase in illumination intensity. A structure of absorption layers that are combined with thin films of different annealing temperatures was developed for a larger output current ratio than traditional photo-sensors. By using a curve scanner (Tektronix $577 \mathrm{I}-\mathrm{V}$ ) to measure the photocurrent of the device, we found that poly- $\mathrm{Si}_{0.8} \mathrm{Ge}_{0.2}$ structures have excellent current rates under illumination.

To obtain the optimal APS growth condition, we systematically studied different annealing parameters, such as annealing temperatures $\left(700 \sim 900^{\circ} \mathrm{C}\right)$ with hydrogen content for $30 \mathrm{~min}$ in poly-SiGe films. In this research, the optimal conditions for developing an APS structure, i.e., indium-tin oxide (ITO) $/ \mathrm{n}^{+}-\mathrm{n}-\mathrm{p}-\mathrm{p}^{+}$poly- $\mathrm{Si}_{0.8} \mathrm{Ge}_{0.2}$ films and aluminum (Al)/silicon dioxide $\left(\mathrm{SiO}_{2}\right) / \mathrm{Si}$-substrate, was found and compared to that of a traditional APS. This investigation discusses not only the enhanced optical absorption, but also its other electrical properties. The developed APS has garnered significant interest as a sensing technology because of its potential to achieve high phonon responsivity and excellent electrical properties. Thus, the ultimate goal of this study is to integrate APS, which provides a route for low-cost, chip-scale, and photo-sensing systems.

\section{Experiments and Measurements}

Both oxidized, un-doped crystalline $\mathrm{Si}(100)$ wafers and conventional Si precoated with indium tin oxide (ITO) were used as substrates for the deposition of poly-SiGe films. The Si-substrate was selected for scanning electron microscope (SEM) analysis. A poly-SiGe thin film containing a $n^{+}-n-p-p^{+}$alloy (total thickness $600 n m$ ) was deposited by the LPCVD system.

Poly-Si $1_{-x} \mathrm{Ge}_{\mathrm{x}}$ films were coated with a RF power of $50 \mathrm{~W}$, temperature of $620^{\circ} \mathrm{C}$, and total pressure of $40 \mathrm{~Pa}$. The gas sources used consisted of $\mathrm{SiH}_{4}, \mathrm{PH}_{3}, \mathrm{~B}_{2} \mathrm{H}_{6}$, and $\mathrm{GeH}_{4}$. The flow rate of $\mathrm{SiH}_{4}$ was set to $20 \mathrm{sccm}$, while the flow rate of $\mathrm{GeH}_{4}$ was varied from $300 \mathrm{sccm}$ to $60 \mathrm{sccm}$. After the poly-SiGe film deposition, a $350 \mathrm{~nm}$ ITO layer was deposited using RF sputtering system. The ITO target used in the laboratory had the ratio of In:Sn = 9:1; argon (Ar) gas was used for sputtering.

Finally, the samples were treated with $60 \mathrm{sccm}$ hydrogen content at anneal temperatures ranging from $700{ }^{\circ} \mathrm{C}$ to $900{ }^{\circ} \mathrm{C}$ for $30 \mathrm{~min}$. The developed APS with an ITO (anode)/poly- $\mathrm{Si}_{0.8} \mathrm{Ge}_{0.2}$ films with a ${ }^{+}$-n-p- ${ }^{+}$alloy and $\mathrm{Al}$ (cathode) $/ \mathrm{SiO}_{2} / \mathrm{Si}$-substrate structure was prepared using as-deposited and annealed poly- $\mathrm{Si}_{0.8} \mathrm{Ge}_{0.2}$ films. The thicknesses of each layer based on the growth-rate estimation were controlled, as described in our previous studies [46-48].

For experimental measurement, the chemical composition of the as-deposited films was quantitatively analyzed by an energy dispersive X-ray spectrometer (EDS, Noran Instruments, mod. Vantage v.1.2 made in Fitchburg, WI, USA). The process time was $5 \mathrm{~s}$, and the spectrum range and corresponding lifetime of EDS parameters were operated at $0 / 10 \mathrm{keV}$ and $100 \mathrm{~s}$, respectively. The crystal structure of the poly-SiGe film was evaluated by a Rigaku X-ray diffraction (XRD, Siemens D5000 made in Germany) with the Ni-filtered $\mathrm{Cu} \mathrm{K} \mathrm{K}_{\alpha}$ radiation. The surface morphologies of the deposited films were examined by a SEM instrument (Hitachi S-4100 made in Japan). The working voltage, magnifying rate, and corresponding distance of SEM parameters were set at $15 \mathrm{KV}, 30 \sim 220 \mathrm{~K}$, and 
9.6 16 mm, respectively. The film thickness was measured with an alpha-step-200 profilemeter supplied by Tencor. To measure the optical gain values of the proposed APS, currentvoltage (I-V) curves were plotted with a curve tracer (Tektronix 577 made in USA). A band-pass filter (500-570 nm) was applied to detect the efficiency of the APS. The average transmission of a green filter used in the $536-550 \mathrm{~nm}$ range was $91.47 \%$. The photo current $\left(I_{p}\right)$ of the developed devices was measured with a commercial tungsten light at a wavelength of $550 \mathrm{~nm}$ and $3 \mu \mathrm{W} / \mathrm{cm}^{2}$ power.

\section{Results and Discussion}

The crystallographic orientation of the film layers depends mainly on the temperature and thickness. In order to discuss the crystallinity of the thin films, the crystallographic orientation and the degree of strain relaxation of the deposited layers were determined by using an X-ray diffraction (XRD). Figure 1 displays the XRD patterns of the poly- $\mathrm{Si}_{0.8} \mathrm{Ge}_{0.2}$ films that were annealed from $700{ }^{\circ} \mathrm{C}$ to $900^{\circ} \mathrm{C}$ for $30 \mathrm{~min}$. The obtained signals correspond to the (111), (220), and (311) crystalline planes of the SiGe alloy, which are characteristics of a material with a SiGe polycrystalline. Due to a lack of thermal energy, only little crystallizations could be found without annealing.

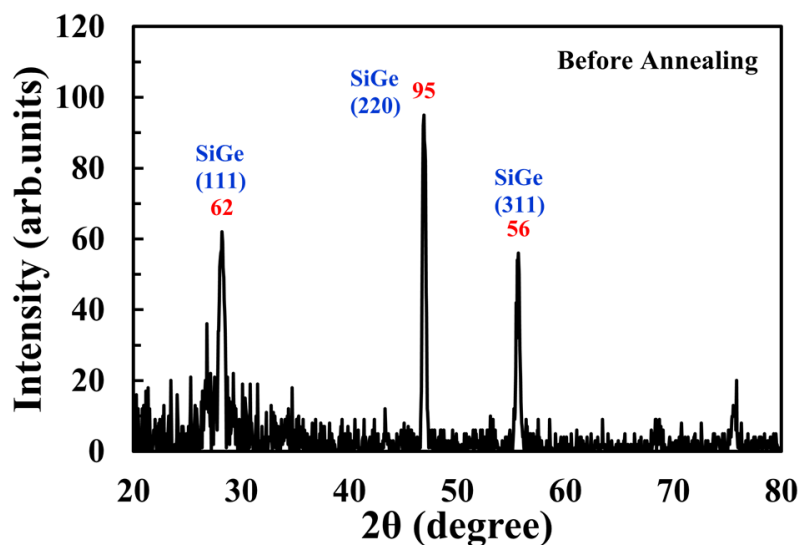

(a)

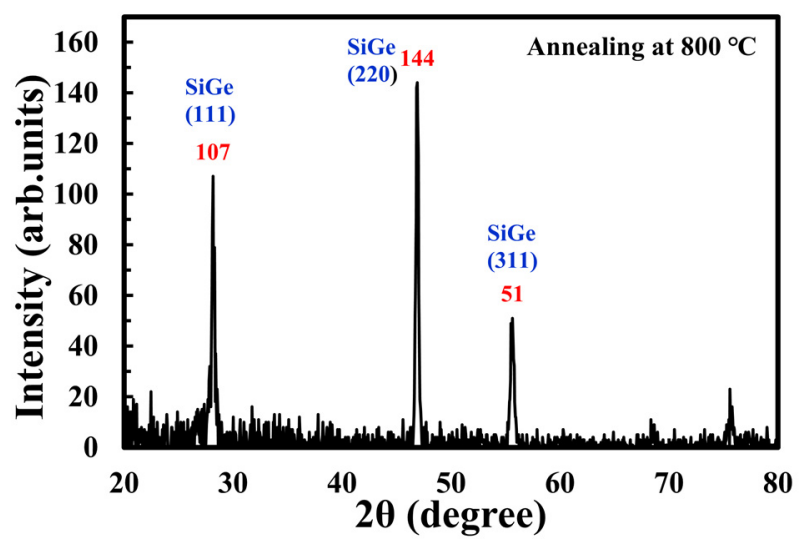

(c)

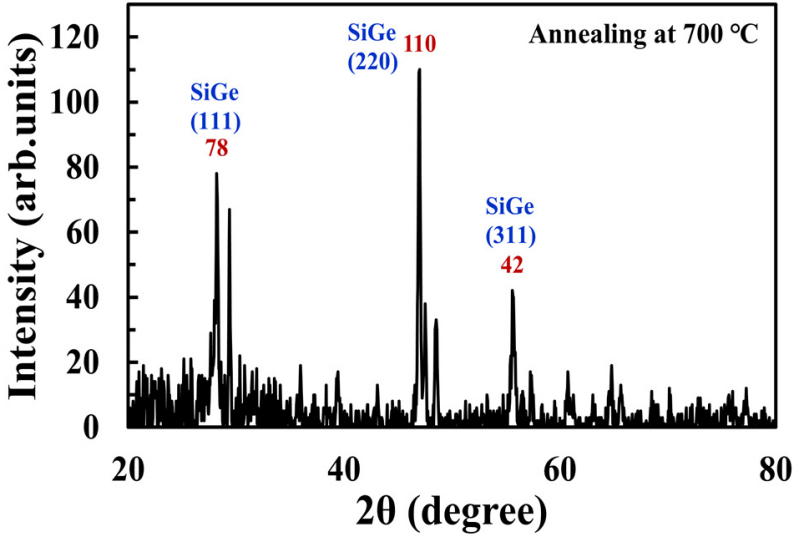

(b)

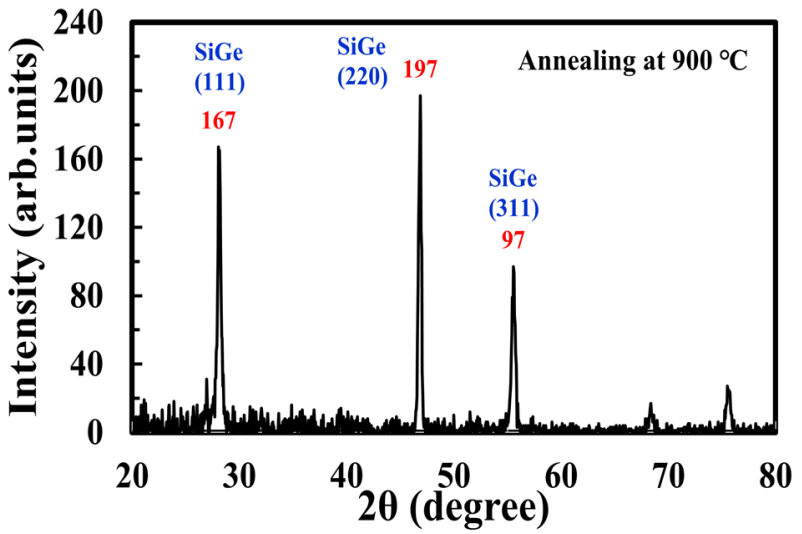

(d)

Figure 1. X-ray diffraction pattern of a polySi ${ }_{0.8} \mathrm{Ge}_{0.2}$ film prepared (a) without annealing, and at different annealing temperatures of (b) $700{ }^{\circ} \mathrm{C}$, (c) $800{ }^{\circ} \mathrm{C}$, and (d) $900{ }^{\circ} \mathrm{C}$ for $30 \mathrm{~min}$.

Since the intensity and sharpness of the three diffraction peaks increased with an annealing temperature up to $800{ }^{\circ} \mathrm{C}$, we also saw an increase in the crystallinity of the film. As the annealing temperature rose to $700{ }^{\circ} \mathrm{C}$, the peak (111) started to increase, and the films began to crystallize. As the annealing temperature rose to $700{ }^{\circ} \mathrm{C}$, an even higher increase in peak values of $\mathrm{SiGe}$ (111) and SiGe (220) were observed, while the peak value of SiGe (311) 
dropped by $25 \%$. When the annealing temperature started to increase the crystallinity and the annealing temperature reached $800{ }^{\circ} \mathrm{C}$, there was a tremendous increase in all three peak values of SiGe (111), SiGe (220), and SiGe (311) up to $100 \%$, compared with those without annealing. This temperature was high enough to cause the thermal energy to trigger crystallization, especially for the SiGe (311) diffraction patterns. However, as the annealing temperature further increased up to $900{ }^{\circ} \mathrm{C}$, all SiGe-intensity peaks reached the highest value for diffraction patterns: 167 for (111), 197 for (220), and 97 for (311), respectively. The electron diffraction patterns contained crystallographic orientation characteristic of the $\mathrm{SiGe}$ polycrystalline structure. We concluded that the SiGe film deposited at $800{ }^{\circ} \mathrm{C}$ is best for crystallographic orientation.

Since the poly- $\mathrm{Si}_{0.8} \mathrm{Ge}_{0.2}$ films employed in the APS were deposited directly in consequent, the surface morphologies of the deposited films may have affected the characteristics of the device. Figure $2 \mathrm{a}-\mathrm{d}$ show the SEM images $\left(2 \times 2 \mu \mathrm{m}^{2}\right)$ of the poly-Si $\mathrm{i}_{0.8} \mathrm{Ge}_{0.2}$ films with and without annealing at different temperatures. Based on the diagrams in Figure $2 b, c$, the grain size and surface roughness of the film morphologies initially increased with the increasing annealing temperature and reached saturation at $800{ }^{\circ} \mathrm{C}$, then decreased dramatically as the annealing temperature rose to $900{ }^{\circ} \mathrm{C}$, as seen in Figure $2 \mathrm{~d}$. This is attributed to the thermal energy provided by the annealing temperature that transferred the surface morphology and reached the most poly-crystalline with saturation at $800{ }^{\circ} \mathrm{C}$ [43-45]. However, at the annealing temperature of $900^{\circ} \mathrm{C}$, surface roughness decreased dramatically (Figure 2d). This is because the energy supplied at the high temperature generated defects for the deposition material. This phenomenon is consistent with the XRD patterns illustrated in Figure 1. Thus, with the LPCVD system, the best annealing temperature for the deposition of the best poly-crystalline film is $800{ }^{\circ} \mathrm{C}$ for $30 \mathrm{~min}$.

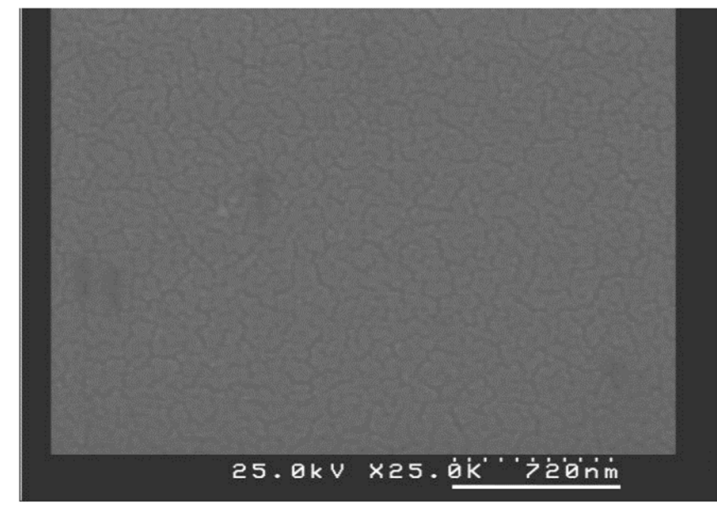

(a)

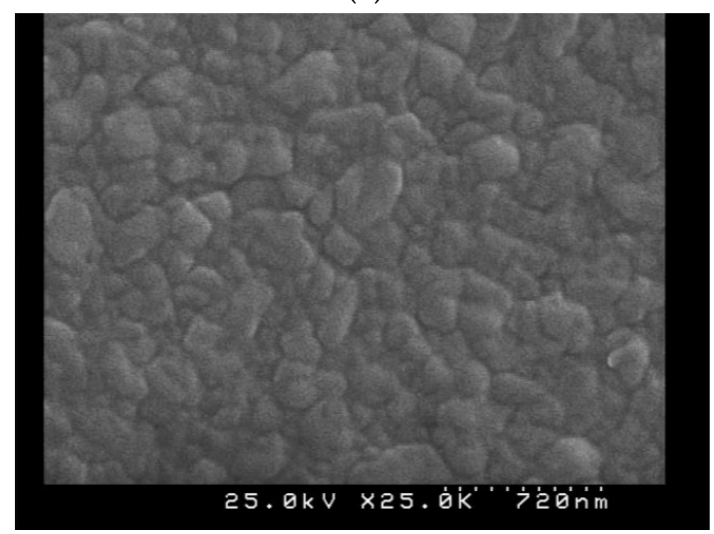

(c)

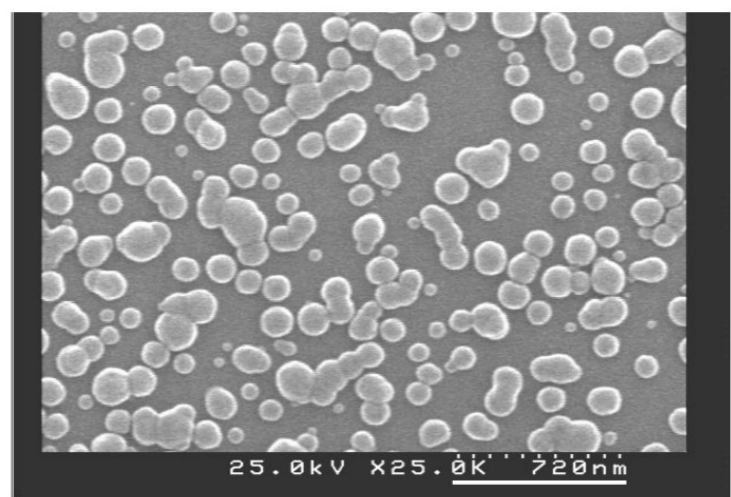

(b)

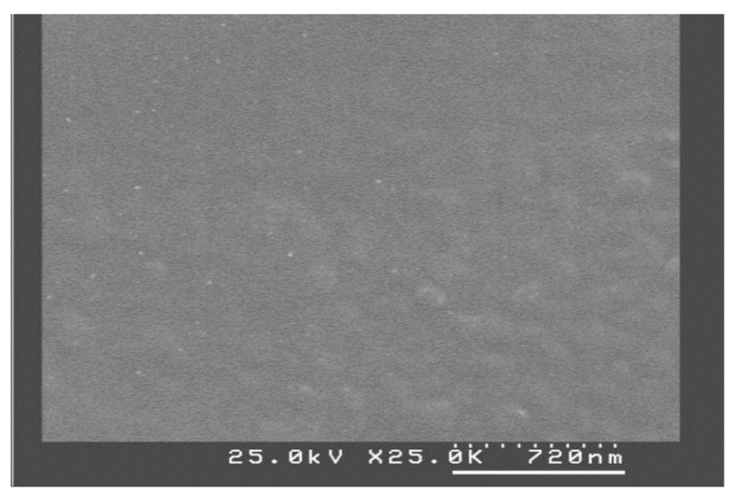

(d)

Figure 2. SEM images of poly- $\mathrm{Si}_{0.8} \mathrm{Ge}_{0.2}$ film deposited (a) without annealing, and at different annealing temperatures of (b) $700{ }^{\circ} \mathrm{C}$, (c) $800{ }^{\circ} \mathrm{C}$, and (d) $900{ }^{\circ} \mathrm{C}$ for $30 \mathrm{~min}$. 
The composition of the poly- $\mathrm{Si}_{0.8} \mathrm{Ge}_{0.2}$ layers was evaluated with an EDS chemical analysis and related to the contrast observed in the SEM image. Figure 3 depicts the X-ray counts from Ge and Si atoms, which represented the atomic percentage of each element. The atomic percentage of the Si:Ge ratio for the chemical composition was approximately 80:20 (denoted $\mathrm{Si}_{0.8} \mathrm{Ge}_{0.2}$ ). Meanwhile, the XRD spectra was applied to obtain the structure of the $\mathrm{Si}_{0.8} \mathrm{Ge}_{0.2}$ films, which showed both apparent $\mathrm{Si}$ and Ge peaks in accordance with the $\mathrm{X}$-ray counts.

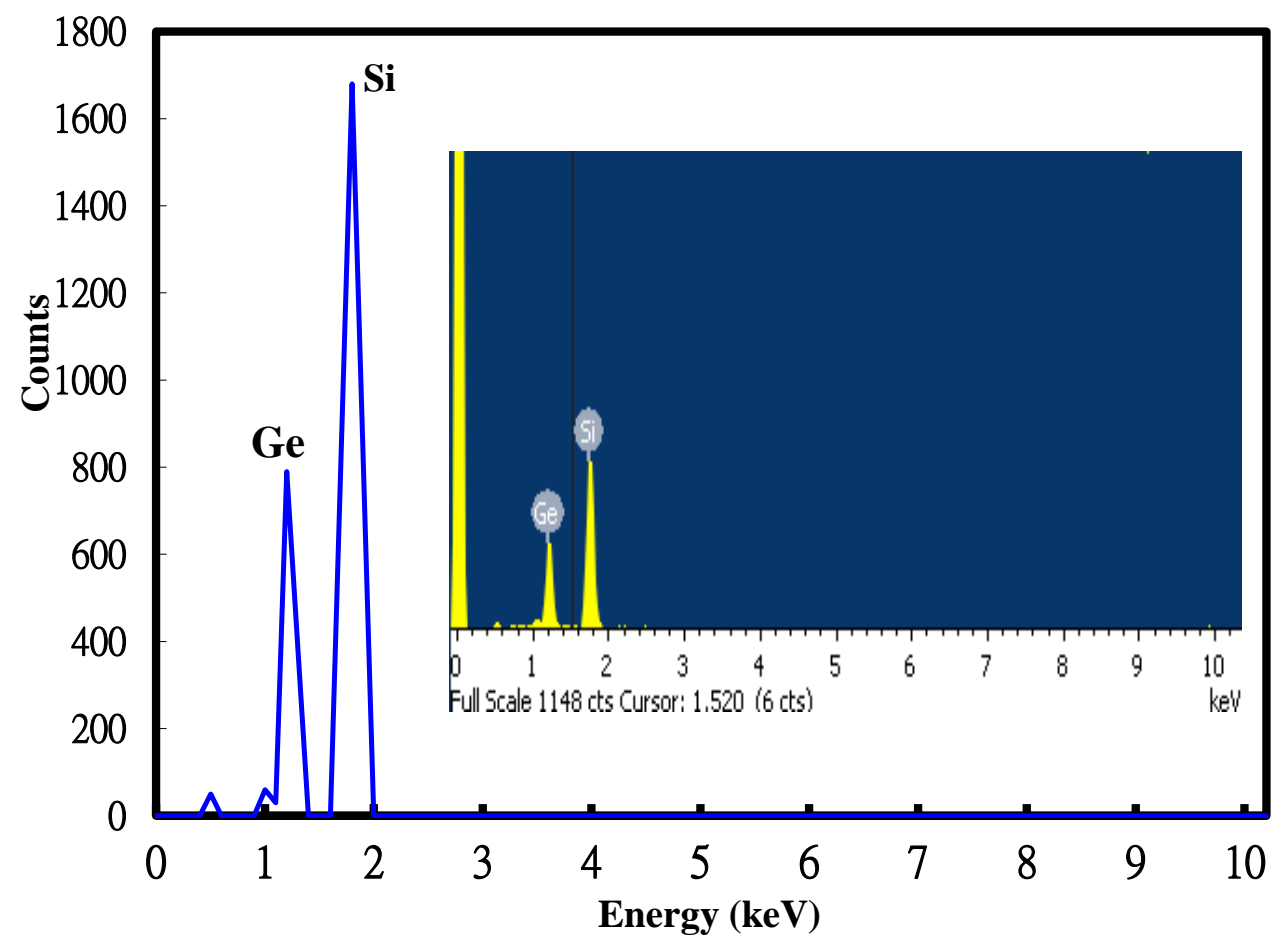

Figure 3. Energy dispersive X-ray spectrometer (EDS) analysis of the deposited $\mathrm{Si}_{0.8} \mathrm{Ge}_{0.2}$ films.

A schematic diagram of the APS structure designed for the present work is shown in Figure $4 \mathrm{a}$. The proposed structure consisted of poly- $\mathrm{Si}_{0.8} \mathrm{Ge}_{0.2}$ films with $\mathrm{n}^{+}-\mathrm{n}-\mathrm{p}-\mathrm{p}^{+}$layers inserted between the cathode Al and the anode ITO substrate. The APS in this study had a width of $200 \mu \mathrm{m}$, a length of $1000 \mu \mathrm{m}$, and a height of $600 \mu \mathrm{m}$. After the deposition process was completed, the contaminated regions were etched out by a buffer solution. Lastly, a $500 \mathrm{~nm}$ Al layer, made up of a cathode electrode, was evaporated and used as the mask of plasma etching to define the device area $\left(\sim 8 \mathrm{~mm}^{2}\right)$. A cross-sectional SEM image of the sample annealed at $800{ }^{\circ} \mathrm{C}$ was taken (Figure $4 \mathrm{~b}$ ). In this image the poly$\mathrm{Si}_{0.8} \mathrm{Ge}_{0.2}$ sandwiched structure exhibited clear and sharp boundaries between the layers with no threading dislocations, which was consistent with the proposed structure shown in Figure 4a. With the above results, we believe that the current fabrication process and degree of precision can be used in photo-sensing applications and optical communication systems. 


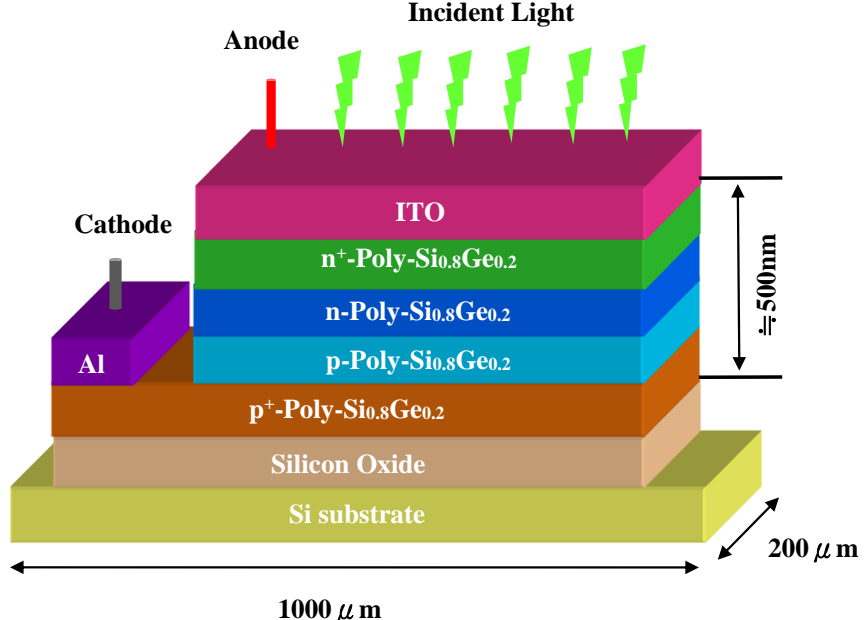

(a)

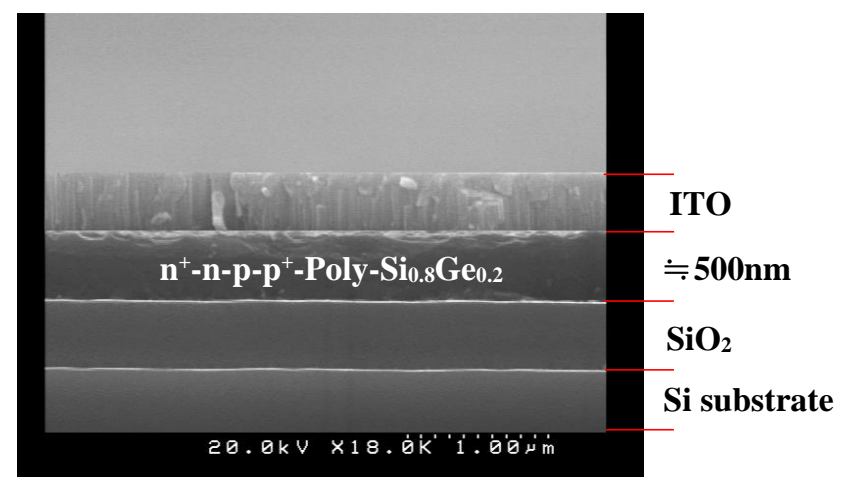

(b)

Figure 4. (a) Indium tin oxide (ITO) $/ \mathrm{n}^{+}-\mathrm{n}-\mathrm{p}-\mathrm{p}^{+}$polySi ${ }_{0.8} \mathrm{Ge}_{0.2}$ film and schematic APS device with aluminum $(\mathrm{Al})$ / silicon dioxide $\left(\mathrm{SiO}_{2}\right) / \mathrm{Si}$-substrate structure and $(\mathbf{b})$ cross-section SEM photo of the developed APS (30 $\mathrm{mm}^{2}$ dimension).

The bottom-left axis of Figure 5 graphs the current-voltage (I-V) curves of the photo current $\left(I_{p}\right)$ under $3-\mu \mathrm{W} / \mathrm{cm}^{2}$ incident light among four APS devices treated with and without different annealing temperatures, i.e., $700{ }^{\circ} \mathrm{C}, 800{ }^{\circ} \mathrm{C}$, and $900{ }^{\circ} \mathrm{C}$ for $30 \mathrm{~min}$. It is worth noting that the $I_{p}$ of all the APS devices increased with increasing the reverse biased voltages $\left(V_{R}\right)$. All the APS photocurrents with the annealing treatment showed better values than those without the annealing treatment. The $I_{p}$ value annealed at $800{ }^{\circ} \mathrm{C}$ was the largest and increased by about $70 \%$, compared with the none-annealing value.

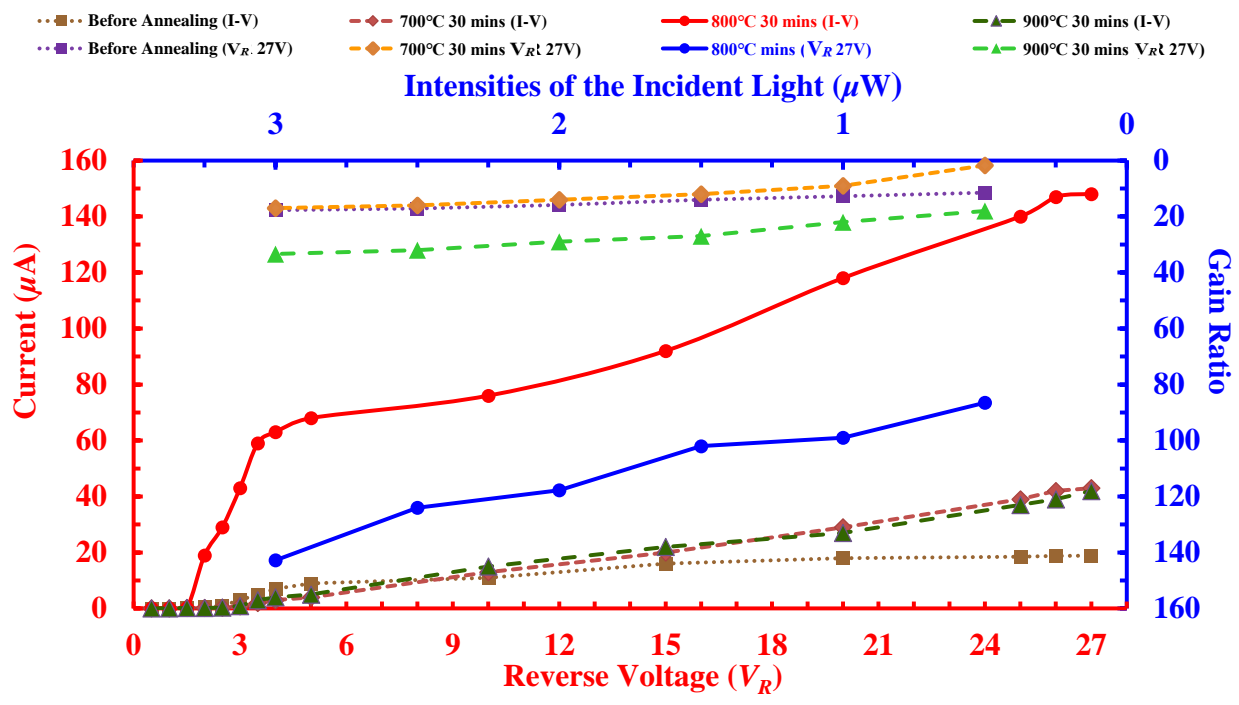

Figure 5. The current-bias voltage (I-V) curves of poly- $\mathrm{Si}_{0.8} \mathrm{Ge}_{0.2}$ films under $3-\mu \mathrm{W}$ incident light power (bottom-left axes) and gain ratio curves versus using a reverse bias voltage up to $27 \mathrm{~V}$ (top-right axes). The APS devices were prepared with as-deposited and annealed poly- $\mathrm{Si}_{0.8} \mathrm{Ge}_{0.2}$ films at $700{ }^{\circ} \mathrm{C}$ to $900{ }^{\circ} \mathrm{C}$ for $30 \mathrm{~min}$.

In order to confirm that the photocurrent multiplication is effective for the APS device developed, the optical sensing gain ratio $(G)$ was calculated using the following formula $[49,50]$ :

$$
G=\left[\frac{I_{p}-I_{d}}{q}\right] \times\left(\frac{E}{P_{\text {in }}}\right)
$$


where $I_{p}$ is the photocurrent, $I_{d}$ is the dark-current, $P_{i n}$ is the input power, $E$ is the energy of the incident photon, and $q$ is electron charge. The wavelength of the radiation can be used for the APS. Therefore, energy of the incident radiation is Planck's constant $h$ multiplied by the frequency $(\lambda)$. The equation can be expressed as:

$$
G=\left[\frac{I_{p}-I_{d}}{q}\right] \times\left(\frac{h c}{P_{i n} \lambda}\right)
$$

where $c=2.998 \times 10^{8} \mathrm{~m} / \mathrm{s}, h=6.626 \times 10^{-34} \mathrm{~J} \cdot \mathrm{s}$, and $q=1.6 \times 10^{-19} \mathrm{C}$. In Equation (2), the optical gain ratio $G$ is calculated from the measured data $P_{i n}$ and $\lambda$. The top-right axis of Figure 5 shows the gain ratio versus the intensities of the incident light. Both the $P_{\text {in }}$ and $\lambda$ were calculated for the investigated APS with the peak wavelength at $550 \mathrm{~nm}$, under the maximum $27-\mathrm{V}$ reverse biasing voltage. In the top-right axis of Figure 5, the biased voltage reached saturation at $3 \mu \mathrm{W} / \mathrm{cm}^{2}$, while the APS at $800{ }^{\circ} \mathrm{C}$ annealing temperature processed the maximum optical gain ratio of 143 approximately $700 \%$ higher than the none-annealing type. These results agree with the experimental data in the bottom-left axis of Figure 5.

The responsivity $\left(\boldsymbol{R}_{\text {resp }}\right)$ is defined as the ratio of the detected photocurrent $\left(I_{p}\right)$ and the absorbed optical power $\left(P_{\text {opt }}\right)$. The top-right axis of Figure 6 describes the $\boldsymbol{R}_{\text {resp }}$-values (in $\mathrm{A} / \mathrm{W})$ as a function of the biasing voltages with respect to the different annealing conditions of the developed APS devices at $3-\mu \mathrm{W} / \mathrm{cm}^{2}$ incident power and $550 \mathrm{~nm}$ wavelength. Moreover, the responsivity at the $800{ }^{\circ} \mathrm{C}$ annealing condition of the developed poly-Si $\mathrm{S}_{0.8} \mathrm{Ge}_{0.2}$ APS device also increased to about $96 \%$ as compared with the none-annealing APS, thus confirming its good photo-sensing characteristics applied to the atmospheric particulate matter detection.

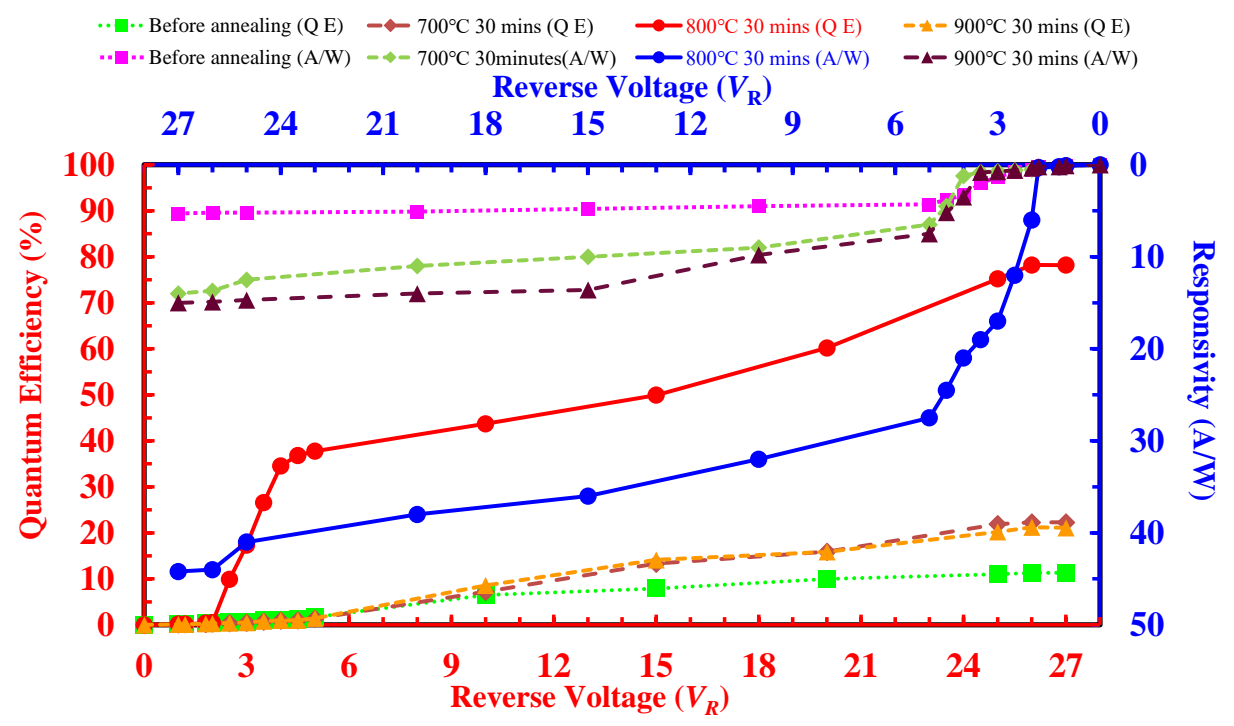

Figure 6. The variation of the responsivity $\left(\boldsymbol{R}_{\text {resp }}\right.$, top-right axes) and quantum efficiency $\left(\eta_{Q E}\right.$, bottom-left axes) with the $3-\mu \mathrm{W} / \mathrm{cm}^{2}$ incident light at reverse bias up to $27 \mathrm{~V}$. The APS devices were prepared with as-deposited and annealed poly-Si $i_{0.8} \mathrm{Ge}_{0.2}$ films at $700{ }^{\circ} \mathrm{C}, 800{ }^{\circ} \mathrm{C}$, and $900{ }^{\circ} \mathrm{C}$ for $30 \mathrm{~min}$.

In order to represent the photoelectric effect of the developed APS devices, we defined the quantum efficiency $\left(\eta_{Q E}\right.$, in $\left.\%\right)$, which is one of the key factors and expressed by the following Equation (3), as the generated electron-hole pairs for each incident photon energy (hv) [51,52]:

$$
\eta_{Q E}=\frac{r_{e}}{r_{p}}=\left(\frac{P_{m}}{q}\right)=\left(\frac{P_{o p t}}{h v}\right)^{-1}
$$

where $r_{p}$ and $r_{e}$ are the photons per second of the incident and the generating photons, respectively. $P_{m}$ is the photocurrent before multiplication. The bottom-left axis of Figure 6 
shows the $\eta_{Q E}-V_{R}$ curve of the developed APS devices at $3-\mu \mathrm{W} / \mathrm{cm}^{2}$ incident power and $550 \mathrm{~nm}$ wavelength. The highest response peaked at $800{ }^{\circ} \mathrm{C}$ annealing condition and improved greatly (96\%) as compared to the none-annealing APS. It is attributed that all the primary generated electrons are assumed to experience a lumped multiplication process immediately in the generation of the secondary electron-hole pairs [52,53].

The schematic diagram for the photo-sensing and optical communication applications is shown in the inset of Figure 7. The proposed APS was connected to an IC (LM358), which was used as a buffer to prevent attenuation. The resistor-capacitor $\left(\boldsymbol{R}_{\mathrm{f}}-\boldsymbol{C}_{\mathrm{f}}\right)$ cut-off filter was connected before and after the buffer to provide actual DC input. The most important figure of merit in the APS characteristics is the avalanche multiplication factor $(M)$ [54], which is similar to those of an APS reverse-biased voltage $\left(V_{R}\right)$ with a ballast resistance $(R)$ and a breakdown voltage $\left(V_{B}\right)$. This can be expressed with the equation below [55]:

$$
M=\frac{1}{1-\left[\frac{\left(V_{R}-R I_{P}\right)}{V_{B}}\right]^{n}}
$$

where the exponent $n$ is related to the impurity distribution in the semiconductor material and the wavelength of the incident light $(h v)$. Figure 7 plots the $M$-values calculated from Equation (4), where the M-values are related to the voltage ratio $\left(V_{A P S} / V_{B}\right)$ from different $n$-values $(=3 \sim 6)$. Normally, the junction voltage $\left(V_{A P S}=V_{R}-R I_{p}\right)$ is smaller than the biased voltage under the developed APS operation. The $M$-values of the plot slowly increased with the small $V_{A P S} / V_{B}$-ratios, and rapidly rose with the $V_{A P S} / V_{B}$-value approaching 1. This mechanism can be explained as follows: since the total quantity of electron-hole pairs in the light absorption region is finite, the number of photo-generated carriers will be saturated gradually when the biasing voltage reaches a certain value.

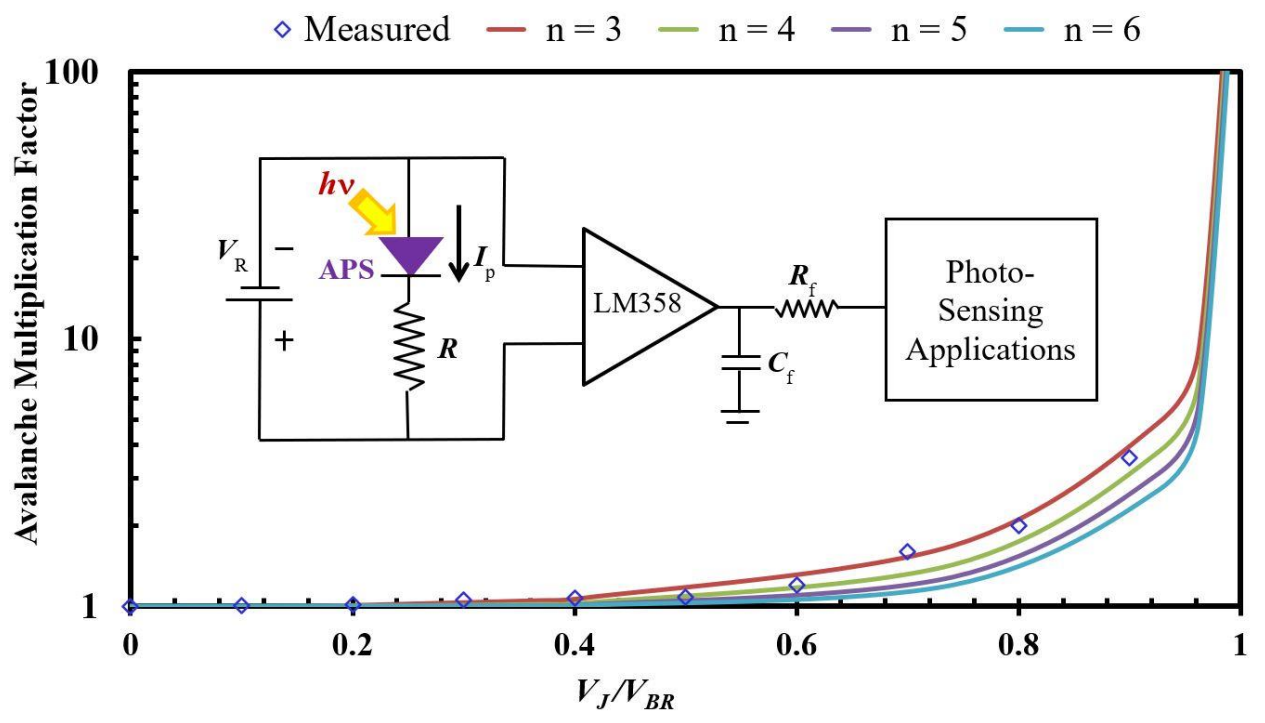

Figure 7. Relationship between the avalanche multiplication factor $(M)$ and the voltage ratio $\left(V_{A P S} / V_{B}\right)$ from different $n$-values (=3 6), which was measured from the circuit diagram for the photo-sensing and optical communication applications, as shown in the inset. These theoretical calculations are also compared with the experimental results under $n=3$ condition.

The poly- $\mathrm{Si}_{0.8} \mathrm{Ge}_{0.2}$ layers exhibit excellent electrical and optical properties for device applications due to proper annealing. This study found that the enhancement of the device performance can be related to the annealing parameters in the $\mathrm{Si}_{1-\mathrm{x}} \mathrm{Ge}_{\mathrm{x}}$ film (SEM comparison shown in Figure 3), indicating that the illumination significantly increases the current generated by the phonon carriers within the Si-base structure. For the developed APS applications in Figure 7, the M-parameter curves by the n-values (from 3 to 6) of Equation (4) were plotted with increasing voltage ratios $\left(V_{A P S} / V_{B}\right)$. Furthermore, the 
optimal avalanche photocurrent ( $\mathrm{M}$ value) applied on the inset circuit diagram can be obtained by taking $n=3$, which is agreed on the $R$-value extracted from the slope of the $\mathrm{I}-\mathrm{V}$ curve at the optimal $800{ }^{\circ} \mathrm{C}$ annealing condition in the bottom-left axis of Figure 5 . Furthermore, the experimental results under $n=3$ conditions are included for the purpose of comparison. A quite good fitness can be found between the calculated and measured results in Figure 7.

\section{Conclusions}

This paper discusses the design and fabrication of a high-performance APS with a $\mathrm{n}^{+}$ $\mathrm{n}-\mathrm{p}-\mathrm{p}^{+}$alloy $/ \mathrm{SiO}_{2} / \mathrm{Si}$-substrate structure using a LPCVD system and the optimal annealing conditions, which are $800{ }^{\circ} \mathrm{C}$ for $30 \mathrm{~min}$, to deposit good poly- $\mathrm{Si}_{0.8} \mathrm{Ge}_{0.2}$ films. Under 3$\mu \mathrm{W} / \mathrm{cm}^{2}$ incident light (with peak wavelength at $550 \mathrm{~nm}$ ) and $27-\mathrm{V}$ biased voltage, the developed APS possesses a maximum photocurrent, responsivity, and quantum efficiency of almost $70 \%, 96 \%$, and $85 \%$, when compared to those of the none-annealing APS type. These excellent detection performances indicate that the proposed APS is a candidate for a low-cost chip for photo-sensing and optical communication applications.

Author Contributions: All authors conceived the idea. T.-L.L. and S.-H.W. worked on the experiments and analyzed the data. Y.-T.C. and J.H. wrote the paper. C.-C.C. (Chung-Cheng Chang) and C.-C.C. (Chau-Chang Chou) edited and revised the paper. All authors participated in the discussion of the results and proofread the paper. J.-J.H. supervised the project. All authors have read and agreed to the published version of the manuscript.

Funding: The authors declare no competing financial interests.

Institutional Review Board Statement: Ethical approval is not required for this study, which excludes this statement.

Informed Consent Statement: This study does not involve humans to the exclusion of this statement.

Acknowledgments: The authors acknowledge financial support from The Ministry of Science and Technology of R.O.C. under contract No. MOST 108-2221-E-019-054.

Conflicts of Interest: The authors declare that they have no conflict of interest.

\section{References}

1. Huang, Z.; Li, C.; Liang, D.; Yu, K.; Santori, C.; Fiorentino, M.; Sorin, W.; Palermo, S.; Beausoleil, R.G. 25 Gbps low-voltage waveguide $\mathrm{Si}-\mathrm{Ge}$ avalanche photodiode. Optics 2016, 3, 793-798. [CrossRef]

2. Aull, B.F.; Duerr, E.K.; Frechette, J.P.; McIntosh, K.A.; Schuette, D.R.; Younger, R.D. Large-Format Geiger-Mode Avalanche Photodiode Arrays and Readout Circuits. IEEE J. Sel. Top. Quantum Electron. 2018, 24, 1-10. [CrossRef]

3. Dravins, D.; Faria, D.; Nilsson, B. Avalanche Diodes as Photon-Counting Detectors in Astronomical Photometry. In Proceedings of the SPIE 2000-The International Society for Optical Engineering, Munich, Germany, 16 August 2000; pp. $298-307$.

4. Lagarto, J.L.; Villa, F.; Tisa, S.; Zappa, F.; Shcheslavskiy, V.; Pavone, F.S.; Cicchi, R. Real-time multispectral fluorescence lifetime imaging using Single Photon Avalanche Diode arrays. Sci. Rep. 2020, 10, 8116. [CrossRef] [PubMed]

5. Grazioso, R.; Aykac, M.; Casey, M.E.; Givens, G.; Schmand, M. APD Performance in Light Sharing PET Applications. IEEE Trans. Nucl. Sci. 2005, 52, 1413-1416. [CrossRef]

6. Li, C.; Li, B.; Qin, S.; Su, J.; He, X.; Guo, X. Effects of Interface States on Ge-On-SOI Photodiodes. J. Electron Devices Soc. 2019, 7, 7-12. [CrossRef]

7. Gity, F.; Daly, A.; Snyder, B.; Peters, F.H.; Hayes, J.; Colinge, C.; Morrison, A.P.; Brian, C. Ge/Si Heterojunction Photodiodes Fabricated by Low Temperature Wafer Bonding. Opt. Express 2013, 21, 17309-17314. [CrossRef] [PubMed]

8. Yotter, R.A.; Wilson, D.M. A Review of Photodetectors for Sensing Light-Emitting Reporters in Biological Systems. IEEE Sens. J. 2003, 3, 288-303. [CrossRef]

9. López, M.; Hofer, H.; Kück, S. Detection Efficiency Calibration of Single-Photon Silicon Avalanche Photodiodes Traceable Using Double Attenuator Technique. J. Mod. Opt. 2015, 62, 1732-1738. [CrossRef]

10. Aull, B.F.; Schuette, D.R.; Young, D.J.; Craig, D.M.; Felton, B.J.; Warner, K. A Study of Crosstalk in a $256 \times 256$ Photon Counting Imager Based on Silicon Geiger-Mode Avalanche Photodiodes. IEEE Sens. J. 2015, 15, 2123-2132. [CrossRef]

11. Gao, J.; Nguyen, S.C.; Bronstein, N.D.; Alivisatos, A.P. Solution-Processed, High-Speed, and High-Quantum-Efficiency Quantum Dot Infrared Photodetectors. Am. Chem. Soc. Photonics 2016, 3, 1217-1222. [CrossRef] 
12. Guo, R.; Zhong, H.; Li, W.; Gu, D.; Jiang, X.; Jiang, Y. Band Engineering of Amorphous Silicon Ruthenium Thin Film and Its Near-Infrared Absorption Enhancement Combined with Nano-Holes Pattern on Back Surface of Silicon Substrate. Appl. Surf. Sci. 2016, 384, 487-491. [CrossRef]

13. Kadri, E.; Krichen, M.; Elleuch, S.; Arab, A.B. Optical Properties of $\mathrm{Si}_{1-\mathrm{x}} \mathrm{Ge}_{\mathrm{x}} / \mathrm{Si}$ Thin Films. Opt. Quantum Electron. 2016, 48, 1-14. [CrossRef]

14. Kang, Y.; Liu, H.D.; Morse, M.; Paniccia, M.J.; Zadka, M.; Litski, S.; Sarid, G.; Pauchard, A.; Kuo, Y.H.; Chen, H.W.; et al. Monolithic germanium/silicon avalanche photodiodes with $340 \mathrm{GHz}$ gain-bandwidth product. Nat. Photonics 2008, 9, 59-63. [CrossRef]

15. Lee, K.H.; Bao, S.; Wang, B.; Wang, C.; Yoon, S.F.; Michel, J.E.; Fitzgerald, A.; Tan, C.S. Reduction of Threading Dislocation Density in Ge/Si Using a Heavily As-Doped Ge Seed Layer. AIP Adv. 2016, 6, 025028. [CrossRef]

16. Son, B.; Lin, Y.; Lee, K.H.; Wang, Y.; Wu, S.; Tan, C.S. High speed and ultra-low dark current Ge vertical p-i-n photodetectors on an oxygen-annealed Ge-on-insulator platform with GeOx surface passivation. Opt. Express 2020, 28, 23978-23990. [CrossRef] [PubMed]

17. Badcock, S.G.; O’NeillE, A.G.; Chester, G. Device and Circuit Performance of SiGe/Si MOSFETs. Solid-State Electron. 2002, 46, 1925-1932. [CrossRef]

18. Littlejohns, C.G.; Nedeljkovic, M.; Mallinson, C.F.; Watts, J.F.; Mashanovich, G.Z.; Reed, G.T.; Garde, F.Y. Next Generation Device Grade Silicon-Germanium on Insulator. Sci. Rep. 2015, 5, 8288. [CrossRef]

19. Low, C.W.; Liu, T.K.; Howe, R.T. Characterization of Polycrystalline Silicon Germanium Film Deposition for Modularly Integrated MEMS Applications. IEEE J. Microelectromech. Syst. 2007, 16, 68-77. [CrossRef]

20. Liu, J.; Beals, M.; Pomerene, A.; Bernardis, S.; Sun, R.; Cheng, J.; Kimerling, L.C.; Miche, J. Waveguide-integrated, Ultra-Low Energy GeSi Electro-Absorption Modulators. Nat. Photonics 2008, 2, 433-437. [CrossRef]

21. Vivien, L.; Pavesi, L. Handbook of Silicon Photonics; Taylor \& Francis Group, LLC: Abingdon-on-Thames, UK, 2008; Chapter 1; pp. 33-37.

22. Dushaq, G.; Rasras, M.; Nayfeh, A. Low Temperature Deposition of Germanium on Silicon Using Radiofrequency Plasma Enhanced Chemical Vapor Deposition. Thin Solid Film 2017, 636, 585-592. [CrossRef]

23. Chen, D.; Guo, Q.; Zhang, N.; Xu, A.; Wang, B.; Li, Y.; Wang, G. High Quality Ge Epilayer on Si (100) With an Ultrathin Si 1 -x $\mathrm{Ge}_{\mathrm{x}} / \mathrm{Si}$ Buffer Layer by RPCVD. Mater. Res. Express 2017, 4, 076407. [CrossRef]

24. Kobayashi, S.; Sakuraba, M.; Matsuura, T.; Murota, J.; Mikoshiba, N. Initial growth characteristics of germanium on silicon in LPCVD using germane gas. J. Cryst. Growth 1997, 174, 686-690. [CrossRef]

25. Gardeniers, J.G.E.; Tilmans, H.A.C.; Visser, C.C.G. LPCVD Silicon-Rich Silicon Nitride Films for Applications in Micromechanics Studied with Statistical Experimental Design. J. Vac. Sci. Technol. A 1996, 14, 2879-2892. [CrossRef]

26. Cheng, Y.T.; Ho, J.J.; Lee, W.; Tsai, S.Y.; Chen, L.Y.; Liou, J.J.; Chang, S.H.; Shen, H.; Wang, K.L. Efficiency Improved by $\mathrm{H}_{2}$ Forming Gas Treatment for Si-Based Solar Cell Applications. Int. J. Photoenergy 2010, 2010, 634162. [CrossRef]

27. Jin, H.; Weber, K.J.; Deenapanray, P.N.K.; Blakers, A.W. Hydrogen Reintroduction by Forming Gas Annealing to LPCVD Silicon Nitride Coated Structures. J. Electrochem. Soc. 2006, 153, G750-G754. [CrossRef]

28. Chen, K.H.; Chien, C.Y.; Lai, W.T.; George, T.; Scherer, A.; Li, P.W. Controlled Heterogeneous Nucleation and Growth of Germanium Quantum Dots on Nanopatterned Silicon Dioxide and Silicon Nitride Substrates. Cryst. Growth Des. 2011, 11, 3222-32226. [CrossRef]

29. Chen, K.H.; Wang, C.C.; George, T.; Li, P.W. The Role of Si Interstitials in The Migration and Growth of Ge Nanocrystallites Under Thermal Annealing in An Oxidizing Ambient. Nanoscale Res. Lett. 2014, 9, 339. [CrossRef]

30. Xu, W.T.; Tu, H.L.; Liu, D.L.; Teng, R.; Xiao, Q.H.; Chang, Q. Self-Assembled SiGe Quantum Dots Embedded in Ge Matrix by Si Ion Implantation and Subsequent Annealing. J. Nanopart. Res. 2012, 14, 682. [CrossRef]

31. Kang, Y.; Zadka, M.; Litski, S.; Sarid, G.; Morse, M.; Paniccia, M.J.; Kuo, Y.H.; Bowers, J.; Beling, A.; Liu, H.D.; et al. EpitaxiallyGrown Ge/Si Avalanche Photodiodes for 1.3 mm Light Detection. Opt. Express 2008, 16, 9365-9371. [CrossRef]

32. Poulton, C.V.; Yaacobi, A.; Cole, D.B.; Byrd, M.J.; Raval, M.; Vermeulen, D.; Watts, M.R. Coherent Solid-State LIDAR with Silicon Photonic Optical Phased Arrays. Opt. Lett. 2017, 42, 4091-4094. [CrossRef]

33. Byeon, D.S.; Cho, C.; Yoon, D.; Choi, Y.; Lee, K.; Baik, S.; Ko, D.H. Epitaxial Growth of Si and SiGe Using High-Order Silanes without a Carrier Gas at Low Temperatures via UHVCVD and LPCVD. Coatings 2021, 11, 568. [CrossRef]

34. Zhang, L.; Dong, T. A Si/SiGe Quantum Well Based Biosensorfor Direct Analysis of Exothermic Biochemical Reaction. J. Micromech. Microeng. 2013, 23, 045011. [CrossRef]

35. Teherani, J.T.; Chern, W.; Antoniadis, D.A.; Hoyt, J.L. Extraction of Large Valence-Band Energy Offsets and Comparison to Theoretical Values for Strained-Si/Strained-Ge Type-II Heterostructures on Relaxed SiGe Substrates. Phys. Rev. B 2012, 85, 205308. [CrossRef]

36. Guenat, O.T.; Generelli, S.; Dadras, M.; Berdondini, L.; de Rooij, N.F.; Koudelka-Hep, M. Generic Technological Platform for Microfabricating Silicon Nitride Microand Nanopipette Arrays. J. Micromech. Microeng. 2005, 15, 2372-2378. [CrossRef]

37. Rusu, C.; Sedky, S.; Parmentier, B.; Verbist, A.; Richard, O.; Brijs, B.; Geenen, L.; Witvrouw, A.; Lärmer, F.; Fischer, F.; et al. New Low-Stress PECVD Poly-SiGe Layers for MEMS. J. Microelectromech. Syst. 2003, 12, 816-825. [CrossRef]

38. Gromova, M.; Mehta, A.; Baert, K.; Witvrouw, A. Characterization and strain gradient optimization of PECVD poly-SiGe layers for MEMS applications. Sens. Actuators A 2006, 130, 403-410. [CrossRef] 
39. Wang, Q.; Vogt, H. With PECVD Deposited Poly-SiGe and Poly-Ge Forming Contacts Between MEMS and Electronics. J. Electron. Mater. 2019, 48, 7360-7365. [CrossRef]

40. Antoni, F.; Fogarassy, E.; Fuchs, C.; Grob, J.J.; Prevot, B.; Stoquert, J.P. Pulsed excimer laser deposition of $\mathrm{Si}_{1-\mathrm{x}} \mathrm{Ge}_{\mathrm{x}}$ thin films. Appl. Phys. Lett. 1995, 67, 2072-2074. [CrossRef]

41. Asafa, T.B.; Witvrouw, A.; Schneider, D.; Moussa, A.; Tabet, N.; Said, S.A.M. Thickness Effect on The Structural and Electrical Properties of Poly-SiGe Films. Mater. Res. Bull. 2014, 49, 102-107. [CrossRef]

42. Voutsas, A.T.; Hatalis, M.K. Structure of As-Deposited LPCVD Silicon Films at Low Deposition Temperatures and Pressures. J. Electrochem. Soc. 1992, 139, 2659-2665. [CrossRef]

43. Colace, L.; Masini, G.; Galluzzi, F.; Assanto, G.; Capellini, G.; Di Gaspare, L.; Palange, E.; Evangelisti, F. Metal-semiconductormetal near-infrared light detector based on epitaxial Ge/Si. Appl. Phys. Lett. 1998, 72, 3175-3177. [CrossRef]

44. Luan, H.C.; Lim, D.R.; Lee, K.K.; Chen, K.M.; Sandland, J.G.; Wada, K.; Kimerling, L.C. High-quality Ge epilayers on Si with low threading-dislocation densities. Appl. Phys. Lett. 1999, 75, 2909-2911. [CrossRef]

45. Gromova, M.; Baert, K.; Van Hoof, C.; Mehta, A.; Witvrouw, A. The novel use of low temperature hydrogenated microcrystalline silicon germanium (lcSiGe:H) for MEMS applications. Microelectron. Eng. 2004, 76, 266-271. [CrossRef]

46. Cheng, Y.T.; Ho, J.J.; Wang, C.K.; Lee, W.; Lu, C.C.; Yau, B.S.; Nain, J.L.; Chang, S.H.; Chang, C.C.; Wang, K.L. Improvement of Organic Solar Cells by Flexible Substrate and ITO Surface Treatments. Appl. Surf. Sci. 2010, 256, 7606-7611. [CrossRef]

47. Ho, J.J.; Chen, C.-Y.; Hsiao, R.Y.; Ho, O.L. The Work Function Improvement on Indium-Tin-Oxide Epitaxial Layers by Doping Treatment for Organic Light-Emitting Device Applications. J. Phys. Chem. 2007, C111, 8372-8376. [CrossRef]

48. Ho, J.J.; Fang, Y.K.; Wu, K.H.; Huang, S.C.; Ju, M.S.; Lin, J.J. High-speed Amorphous Silicon Germanium Infrared Sensors Prepared on Crystalline Silicon Substrates. IEEE Trans. Electron Devices 1998, 45, 2085-2088.

49. Okamura, M.; Suzuki, S. Infrared Photo Detection Using A-Si:H Photodiode. IEEE Photonics Technol. Lett. 1994, 6, 412-414. [CrossRef]

50. Sze, S.M.; Ng, K.K. Physics of Semiconductor Devices, 3rd ed.; Chapter 13; Wiley: Hoboken, NJ, USA, 2007; pp. 663-742.

51. Brennan, K.F. The Physics of Semiconductors with Applications to Optoelectronic Devices; Cambridge University Press: Cambridge, UK, 1999; Chapter 12; pp. 637-643.

52. El-Batawy, Y.M.; Deen, M.J. Analysis and Circuit Modeling of Waveguide-Separated Absorption Charge Multiplication-Avalanche Photodetector (WG-SACM-APD). IEEE Trans. Electron Devices 2005, 52, 335-344. [CrossRef]

53. Kisch, H. Semiconductor Photocatalysis for Chemoselective Radical Coupling Reactions. Am. Chem. Soc. Acc. Chem. Res. 2017, 50, 1002-1010. [CrossRef] [PubMed]

54. Lei, S.; Wen, F.; Ge, L.; Najmaei, S.; George, A.; Gong, Y.; Gao, W.; Jin, Z.; Li, B.; Lou, J.; et al. An Atomically Layered InSe Avalanche Photodetector. Nano Lett. 2015, 15, 3048-3055. [CrossRef]

55. Resetar, T.; Munck, K.D.; Haspeslagh, L.; Rosmeulen, M.; Süss, A.; Puers, R.; Hoof, C.V. Development of Gated Pinned Avalanche Photodiode Pixels for High-Speed Low-Light Imaging. Sensors 2016, 16, 1294. [CrossRef] [PubMed] 